danger threshold was perhaps not so far wrong. It would be a pity if this book, which may well become a standard reference, were to condone and help to perpetuate imprecise and often counter-productive terminologies and classifications. HaRvEY GoLDSTEIN

${ }^{1}$ Rantakallio, P., Annls Paediat. Fenn., 14, 66 (1968).

${ }^{2}$ Butler, N. R., and Alberman, E. D., Pcrinatal Problems (Livingstone, Edinburgh, 1969).

\section{Organizing Books}

Classified Library of Congress Subject Headings. Edited by James G. Williams, Martha L. Manheimer and Jay E. Dailey. Volume I: Classified List. Pp. v +250 . Volume II: Alphabetic List. Pp. v+250. (Marcel Dekker: New York, November 1972.) \$25 each volume.

THE Library of Congress system, devised for the organization of knowledge in the collections of that library, consists of two parts: a classification scheme for the arrangement of books and a subject headings list for the arrangement of alphabetical catalogues. Nowadays we are aware that such a system should be integrated; that class numbers and subject headings are merely different ways of expressing the same concepts; that the cross references in an alphabetical subject catalogue should reflect the structure of a classification scheme. We are able to design an index language that can be used both for the shelf arrangement of documents and for the construction of any type of catalogue or index. When the LC system was devised the two parts were taken to have different aims and principles. They were developed independently and bear little relation to each other. Even as separate entities they are not particularly good examples of their kind. The classification scheme has never claimed to show the structure of knowledge as seen by specialists. Its out-of-date method of attempting to enumerate all the possible subjects of documents was doomed to failure from the start and inevitably leads to inconsistency and cross-classification. The subject headings notoriously fail to obey even the few rules they profess.

The aim of the work under review is to improve the efficiency of libraries using the LC system. It is addressed to the research worker as well as the librarian and is meant to be used by both. Volume I is a completely new contribution in that it arranges the subject headings in the order of the classification scheme. The preface admits that "research now confirms what reference librarians and their nonprofessional peers long ago concluded: as a collection and its catalogue grow in size, the usefulness of a subject head- ing list applied in a dictionary catalogue decreases finally to the point of virtual ineffectiveness". As a remedy that avoids the task of recataloguing a large library, the authors offer this classified list. For the librarian it is supposed to unify the processes of allocating class numbers and subject headings to documents. For the user it is supposed to perform the function of a classified catalogue in providing more effective access to related subjects in a collection. Volume II consists of an alphabetical list of the subject headings to serve as an index to the classified sequence. The main Library of Congress publication, Subject Headings, is not considered suitable for this purpose since the subject headings themselves are obscured by a mass of cross-references and instructions.

It is difficult to share the authors' optimism about the value of their work. In the first place it has always been recognized that no published scheme or its index is a suitable guide to the contents of a particular collection. It will inevitably contain many subjects not represented in the library and will fail to list many that are. In the second place, although the authors refer to some shortcomings in the L C system they give no indication that they have taken others into account. They claim, for example, that the classified list eliminates the necessity for the crossreferences in the subject headings list. If we were dealing with a first-class classification there would be something in this, but LC is a limited classification. The cross-references in the subject headings list freqently supplement rather than duplicate the relationships shown in the classified order. Furthermore, the correspondence between individual class numbers and headings is far less precise than the presentation implies. This low correlation is dealt with in some detail by J. P. Immroth in his Analysis of Vocabulary Control in Library of Congress Classification and Subject Headings (Littleton, Colorado: Libraries Unlimited, 1971).

The idea of applying modern ideas to improve an old system is laudable, but the work under review falls far short of its aim. In fact, the L C system is so faulty that many people would deplore the use of time, money and intellectual effort to prolong its life. They would not like to see repeated in England the recent experience in USA of many large libraries adopting the system-an experience, incidentally, that invalidates the argument that wholesale reorganization of large libraries is unthinkable. No doubt many librarians will continue to defend the use of the system for some purposes, but even they would have to admit that it is least satisfactory in dealing with science. Even with the new publication the scientific research worker cannot hope for any- thing like an adequate information retrieval service from libraries organized by the ICC system. D. W. LANGRIDGE

\section{Ultracentrifugal Topics}

Ultracentrifugation of Macromolecules: Modern Topics. By J. W. Williams. Pp. xvi+118. (Academic: London and New York, January 1973.) \$9.50.

IN the year that marks the 50th anniversary of the ultracentrifuge, it is particularly fitting to take notice of the latest contribution from one who was present at the birth. Professor J. W. Williams is justly renowned for his contributions to the theory and use of the ultracentrifuge, an instrument which has played so great a part in our understanding of quantitative relationships among biological macromolecules. Without detracting from the sometimes spectacular advances made by others, it is surely a remarkable achievement on his part to have been consistently in the forefront of innovation and refinement. This volume provides a short account of some areas of special interest to the author, where recent progress has enabled earlier barriers of intractability to be overcome.

The section on the study of synthetic polymers by sedimentation equilibrium shows how the complications arising from polydispersity accompanied by thermodynamic non-ideality can be minimized; it should facilitate the determination of reliable values of molecular weight in these systems.

The field of protein interaction has been one of remarkable development over the past few years, and the sections devoted to this topic provide an excellent illustration of the depths of analysis which Rayleigh optics (usually allied to computer processing of data) have made possible. The determination of equilibrium constants in associating systems also exhibiting non-ideality is indeed impressive when one reflects on how slight are the deviations presented by any one experiment.

A chapter on the determination of size distributions is mostly of historical interest; but the final chapter, on a combination of velocity and equilibrium methods in the study of protein subunits, illustrates the continued value of velocity measurements.

The book concludes with short appendices devoted to the fundamental theory of the ultracentrifuge, and to the effects of molecular heterogeneity. They provide an admirable introduc. tion to the subject, in simply-formulated mathematical terms. If the general approach is that of the physical chemist, the book can nevertheless be studied profitably by all who are concerned with the quantitative interpretation of ultracentrifugal experiments.

J. M. CREeth 